\title{
CORRIGENDUM
}

\section{A highly penetrant form of childhood apraxia of speech due to deletion of $16 \mathrm{p} 11.2$}

Evelina Fedorenko, Angela Morgan, Elizabeth Murray, Annie Cardinaux, Cristina Mei, Helen Tager-Flusberg, Simon E Fisher and Nancy Kanwisher

European Journal of Human Genetics (2016) 24, 310; doi:10.1038/ejhg.2015.230

Correction to: European Journal of Human Genetics (2016) 24, 302-306; doi:10.1038/ejhg.2015.149; published online 15 July 2015

Dr Simon E Fisher's affiliation unfortunately contained an error. This has been corrected in the online version and the print version, which also appears in this issue. 